\title{
Pulsed Laser Annealing Effect on Optical and Structural Properties of $\mathrm{ZnS} / \mathrm{ZnSe}$ Heterostructures
}

\begin{abstract}
H. Howari
Physics Department, Deanship of Educational Services, Qassim University, Buraidah, Kingdom of Saudi Arabia

* Corresponding author email: haidarh1@yahoo.com

Received: 09 October 2019 / Revised: 23 October 2019 / Accepted: 28 October 2019 / Published: 29 October 2019

ABSTRACT

Studies of pulsed laser annealing (PLA) on semiconductor thin films were performed to examine changes of the optical and structural parameters due to the laser heat. Thin films of $\mathrm{ZnS} / \mathrm{ZnSe}$ were deposited on quartz substrates at a pressure of $8.2 \times 10^{-6} \mathrm{mbar}$ using PVD technique. These thin films were annealed at different laser powers using $\mathrm{CO}_{2}$ pulsed laser. Transmission and reflection spectra were recorded before and after the annealing process. A decrease in the transmission and reflection spectra after annealing is observed. The absorption coefficient, refractive index, damping coefficient and dielectric constant were calculated before and after the annealing process. Changes in the optical parameters are found after the annealing process. The energy band gaps of $\mathrm{ZnS}$ and $\mathrm{ZnSe}$ have been determined. Upon annealing, an increase in the absorption coefficient is observed which is due to an improvement in the granular nanostructure of the $\mathrm{ZnS} / \mathrm{ZnSe}$ thin films. XRD patterns of the prepared samples were obtained before and after the annealing procedure and revealed an enhancement in the crystallite structure upon annealing.
\end{abstract}

Keywords: Optical properties; Transmission, X-ray diffraction; Annealing, Heterostructures, Pulsed Laser

\section{Introduction}

II-VI compound semiconductor heterostructures have currently draw considerable attention due to their outstanding electronic and optoelectronic properties [1,2]. Wide bandgap II-VI structures are excellent candidates for electronic and optoelectronic devices. ZnS has always been a promising material for blue and UV light emitting diodes and laser diodes [1-4]. When $\mathrm{ZnS}$ combines with other materials such as $\mathrm{ZnSe}$, it produces a stimulating and potentially effective heterostructures such as $\mathrm{ZnS} / \mathrm{ZnSe}$ systems [58]. Such systems are used as phototransistors in the UV detection [4]. $\mathrm{ZnS}$ and $\mathrm{ZnSe}$ exist in two crystal forms, cubic zincblende and hexagonal wurtzite crystal structures. $\mathrm{ZnS}$ has wide direct bandgap of about $3.50 \mathrm{eV}$ in the $\mathrm{UV}$ region; it is used as a key material for blue light emitting diodes and other optoelectronic devices [1,2]. On the other hand, ZnSe is also a compound direct bandgap semiconductor with a bandgap energy of $2.7 \mathrm{eV}$ [5]. The transmittance of $\mathrm{ZnSe}$ is about
(0.5-15) $\mu \mathrm{m}$ and for $\mathrm{ZnS}$ is up to $10 \mu \mathrm{m}$. These facts make both $\mathrm{ZnS}$ and $\mathrm{ZnSe}$ useful in the field of optical applications such as excellent filters in the IR spectrum and coatings for high power laser windows and as antireflection coatings for solar cells fabrication [2].

The advance of altering surface layers of multilayer structures using pulsed lasers has produced a unique branch of material science. The spatial and temporal control over the heat flow and the energy deposition by these beams has opened a wide range of new applications varying from growing crystals to quenching alloys into metastable states, and from depositing films to purifying surfaces. Pulse laser annealing of semiconductors was first carried out to remove the damage caused by the ion implantation. Nevertheless, laser crystallization techniques were far more successful in converting amorphous $\mathrm{Si}$ into a single-crystal $\mathrm{Si}$ which in turn led to a new production of semiconductor devices [9]. Moreover, pulse laser annealing 
process has the ability of producing materials with impurities concentration over the natural solubility limit. This is due to the rapid heating and cooling occurrence in the material which causes recrystallization, where substitutional impurities diffuse into native lattice sites [10]. The main objective of this research is to investigate changes in the optical and structural properties of $\mathrm{ZnS} / \mathrm{ZnSe}$ heterostructure upon annealing at different laser powers using pulsed laser annealing technique.

\section{Materials and Methods}

Thin films of $\mathrm{ZnS} / \mathrm{ZnSe}$ were deposited on quartz substrates (USA-pat.3636589) using Physical Vapor Deposition (PVD) (Auto 306 Edwards Coating Unit). First, highly cleaned quartz substrates were utilized to prepare the $\mathrm{ZnS} / \mathrm{ZnSe}$ structures. Pure powder of $\mathrm{ZnS}$ and $\mathrm{ZnSe}$ were used for preparation of the structures. Table (1) shows the deposition parameters of the thin films. The thickness of the multilayer was estimated using (FTM) films thickness measurement provided inside the PVD Auto 306 Unit which uses Quartz crystal covered with a thin layer of Gold (electrical vibration) connected directly into a programmed unit to provide the correct reading of the thickness. All of the samples were of good quality.

Table 1: Deposition parameters of ZnS and ZnSe thin films at a temperature of $30{ }^{\circ} \mathrm{C}$.

\begin{tabular}{|c|c|c|}
\hline Material & pressure & Thickness \\
\hline $\mathrm{ZnS}$ & $8 \times 10^{-6} \mathrm{mban}$ & $200 \mathrm{~A}$ \\
\hline $\mathrm{ZnSe}$ & $8 \times 10^{-6} \mathrm{mban}$ & $500 \mathrm{~A}$ \\
\hline
\end{tabular}

Several samples of these thin films were then annealed using $\mathrm{CO}_{2}$ pulsed laser provided with Q-Switch (single pulse) at a wavelength of 10600 $\mathrm{nm}$ and three different laser powers 15, 20 and $30 \mathrm{~W}$.

\section{Optical Measurements}

Transmittance and reflectance spectra of the deposited samples were carried out at room temperature in the spectral range from (2502250) nm using Jasco V-570 UV-VIS-NIR double beam spectrophotometer. Figure (1) displays the transmission spectra of the prepared structures before and after the annealing procedure, where we observe a decrease in the overall transmission after annealing. As revealed in Fig. (1), a shift in the interference peaks to higher wavelengths is seen in addition to a decrease in the amplitude with increasing the annealing power, which can be attributed to the disparities of the structure, morphology and composition of the prepared samples after annealing due to the heat effect.

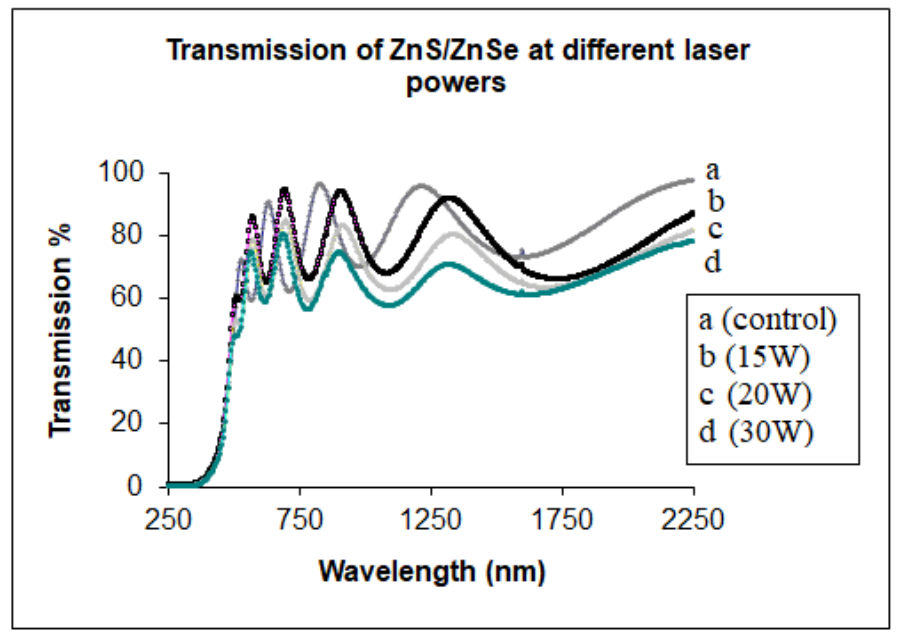

Figure 1: Transmission vs. wavelength of the deposited heterostructures before and after the annealing process.

Figure (2) illustrates the reflectivity spectra of the deposited samples before (control sample) and after annealing. An overall decrease in the reflectivity after annealing is also observed.

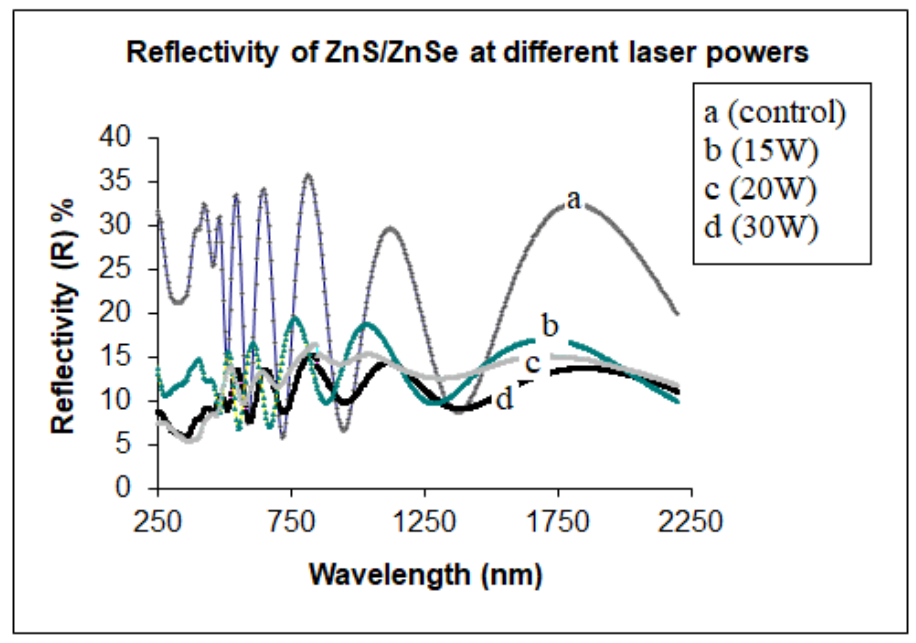

Figure 2: Reflectivity vs. wavelength of the deposited heterostructures before and after the annealing process. 
H. Howari, J. Mod. Mater.; Vol. 6, Issue 1, pp: 23-29, 2019

The absorption coefficient of a direct transition $\alpha_{d}$ is related to the photon energy of light as [10]-

$\alpha_{d}=\frac{A\left(h \boldsymbol{v}-E_{g}\right)^{1 / 2}}{h \boldsymbol{v}}$

For $\quad h v \geq E_{g}$

While the absorption coefficient of indirect transition $\alpha_{i}$ is written as-

$\alpha_{i}=B \frac{\left(h v-E_{g}+E_{p}\right)^{2}}{\exp \left(E_{p} / k T\right)-1}$

For $\left(E_{g}-E_{p}\right)<h v<\left(E_{g}+E_{p}\right)$, and:

$\alpha_{i}=B\left[\frac{\left(h v-E_{g}+E_{p}\right)^{2}}{\exp \left(E_{p} / k T\right)-1}+\frac{\left(h v-E_{g}-E_{p}\right)^{2}}{1-\exp \left(-E_{p} / k T\right)}\right]$ (3)

For $h v>E_{g}+E_{p}$, where $A$ is a typical parameter for particular transitions, $E_{g}$ is optical energy bandgap and $b v$ represents the photon energy. The complex refractive index is given by:

$\tilde{n}=n+i k$

The real part of the refractive index is $n$ and the imaginary part which is known as the extinction coefficient is $k$.

Material response to light can be described by both $n$ and $k$ using the following equation [11]:

$R=\frac{(1-n)^{2}+n^{2} K^{2}}{(1+n)^{2}+n^{2} K^{2}}$

The absorption coefficient and the extinction coefficient of the thin films can be determined using:

$\alpha=2.303 \times \ln \frac{A}{d}=\frac{4 \pi K}{\lambda}$

where $d$ is the thickness of the thin film and $A$ is the absorption.

To estimate the energy bandgap of the semiconductor thin films, equation (1) was used and then plots of $(\alpha \cdot h v)^{2}$ vs. photon energy of $\mathrm{ZnS}$ and $\mathrm{ZnSe}$ were carried out as shown in figures (3-a and b).

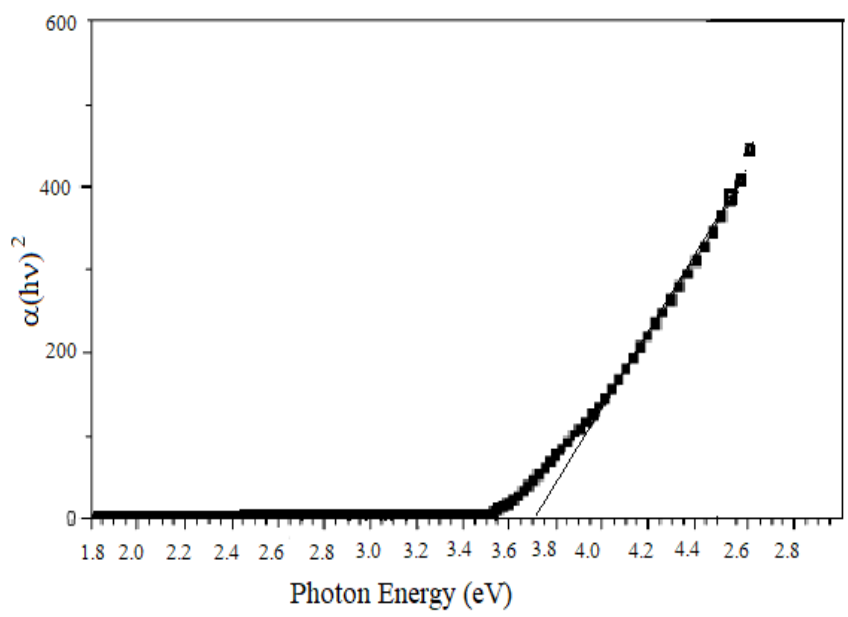

Figure 3a: A plot of $(\alpha \cdot h v)^{2}$ vs. photon energy of $\mathrm{ZnS}$ structures.

The energy bandgap for $\mathrm{ZnS}$ thin film was estimated as $3.68 \mathrm{eV}$ as depicted in figure $3 \mathrm{a}$.

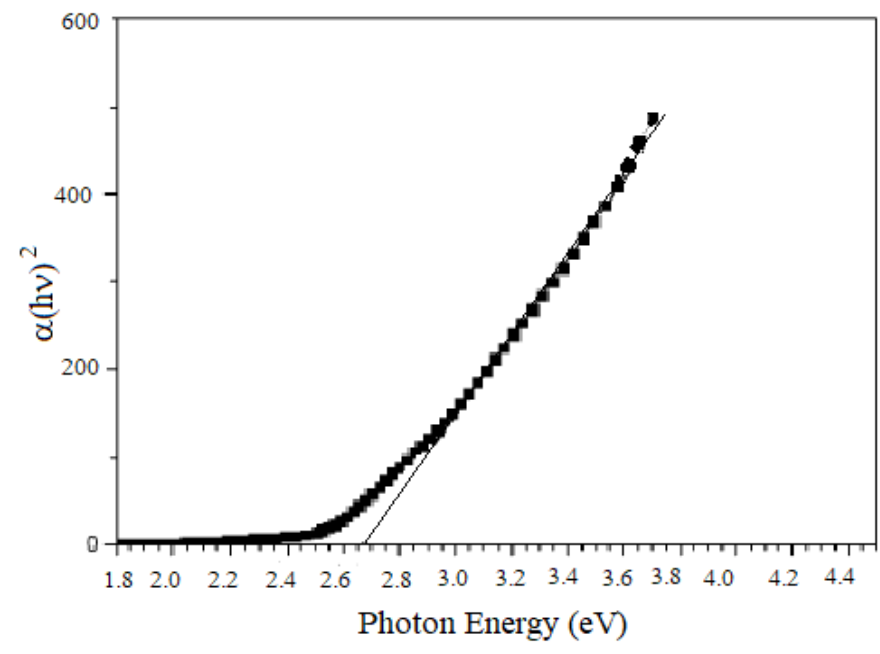

Figure 3b: A plot of $(\alpha \cdot h v)^{2}$ vs. photon energy of ZnSe structures.

On the other hand, the energy bandgap for $\mathrm{ZnSe}$ was found $2.69 \mathrm{eV}$ as presented in figure $3 \mathrm{~b}$. Table (2) shows the direct energy bandgap $\mathrm{E}_{\mathrm{g}}$ of the prepared heterostructures.

Table 2: The direct energy band gap $E_{g}$ of the deposited thin films.

\begin{tabular}{|c|c|c|}
\hline Material & $\mathrm{ZnSe}$ & $\mathrm{ZnS}$ \\
\hline $\begin{array}{c}\text { The energy bandgap } \\
\text { from ref. [4-6] }\end{array}$ & $\begin{array}{c}2.68 \\
(300 \mathrm{~K})\end{array}$ & $3.67(300 \mathrm{~K})$ \\
$\begin{array}{c}\text { The experimental } \\
\text { values of energy } \\
\text { bandgap }\end{array}$ & $\begin{array}{c}2.69 \\
(300 \mathrm{~K})\end{array}$ & $3.68(300 \mathrm{~K})$ \\
\hline
\end{tabular}


Pulsed Laser Annealing Effect on Optical and Structural Properties of ZnS/ZnSe Heterostructures

These results are in good comparison with references [12,13]. Figure (4) shows the absorption coefficient vs. wavelength before and after annealing. As shown in the figure below, when laser power increases the absorption coefficient increases too for the whole wavelength range. Again this increase is accompanied with a shift towards higher wavelengths.

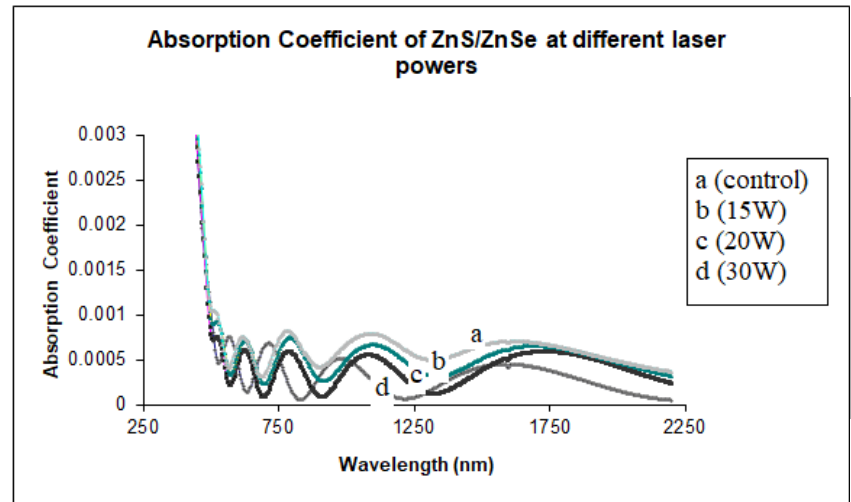

Figure 4: Absorption coefficient vs. wavelength before and after annealing.

When comparing the absorption coefficient values before and after annealing, we find that the greatest change occurs at $30 \mathrm{~W}$ laser power.

The real $\varepsilon_{1}$ and imaginary $\varepsilon_{2}$ parts of the dielectric constant were determined using:

$$
\begin{aligned}
& \varepsilon_{1}=n^{2}-K^{2} \\
& \varepsilon_{2}=2 n K
\end{aligned}
$$

Figures (5-a) and (5-b) show $\varepsilon_{1}$ and $\varepsilon_{2}$ vs. wavelength of the deposited samples before and after annealing. We observe a decrease in $\varepsilon_{1}(\lambda)$ and $\varepsilon_{2}(\lambda)$ upon annealing at different laser powers.

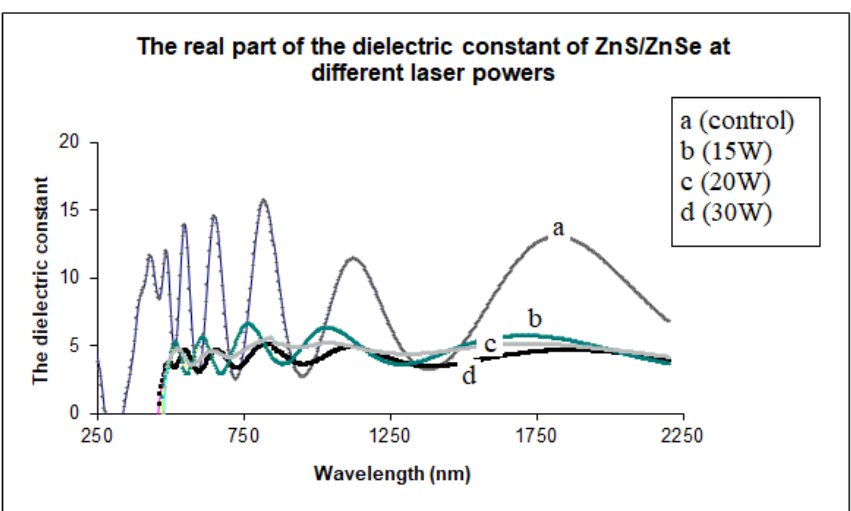

Figure 5-a: An illustration of the real part of the dielectric constant $\varepsilon_{1} v$ s. wavelength of the deposited samples before and after annealing.

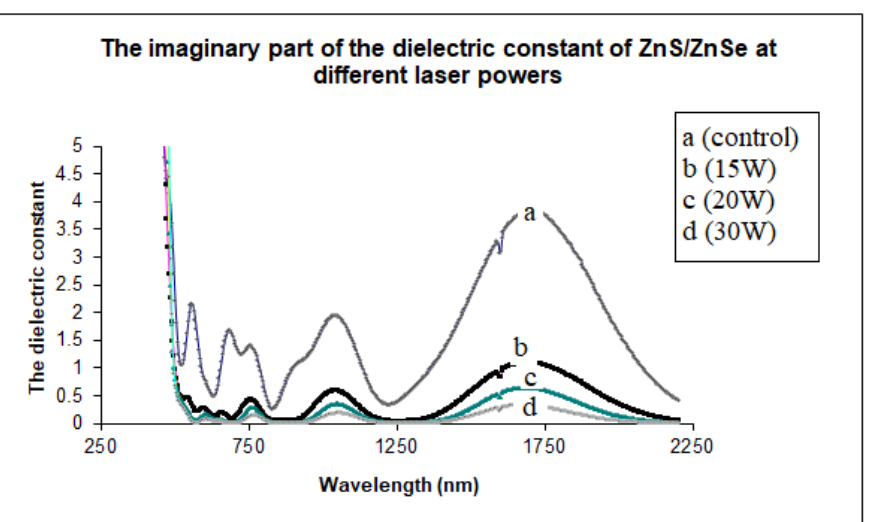

Figure 5-b: An illustration of the imaginary part of the dielectric constant $\varepsilon_{2} v$ s. wavelength of the deposited samples before and after annealing.

This decrease in $\varepsilon_{1}(\lambda)$ and $\varepsilon_{2}(\lambda)$ can be attributed to a decrease in the damping (extinction) coefficient $\mathrm{k}$, as shown in figure (6).

The Damping Coefficient of ZnS/ZnSe at different laser powers

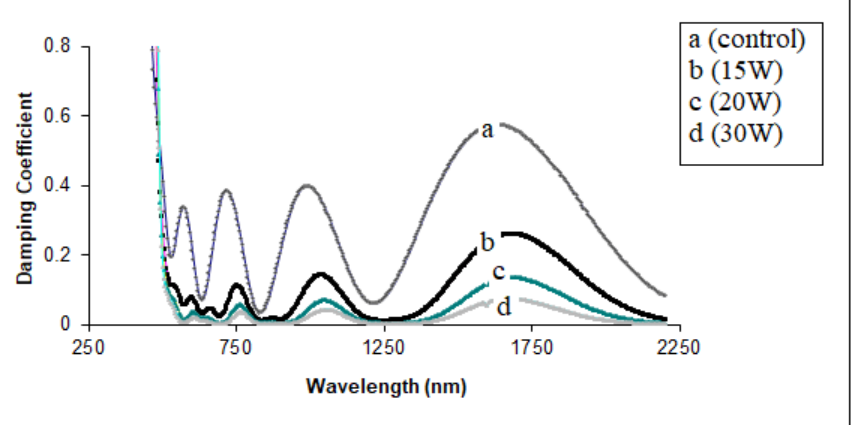

Figure 6: The damping coefficient vs. wavelength before and after annealing.

Moreover, a decrease in the refractive index $(n)$ is witnessed after the annealing process at different laser powers as can be seen in figure (7).

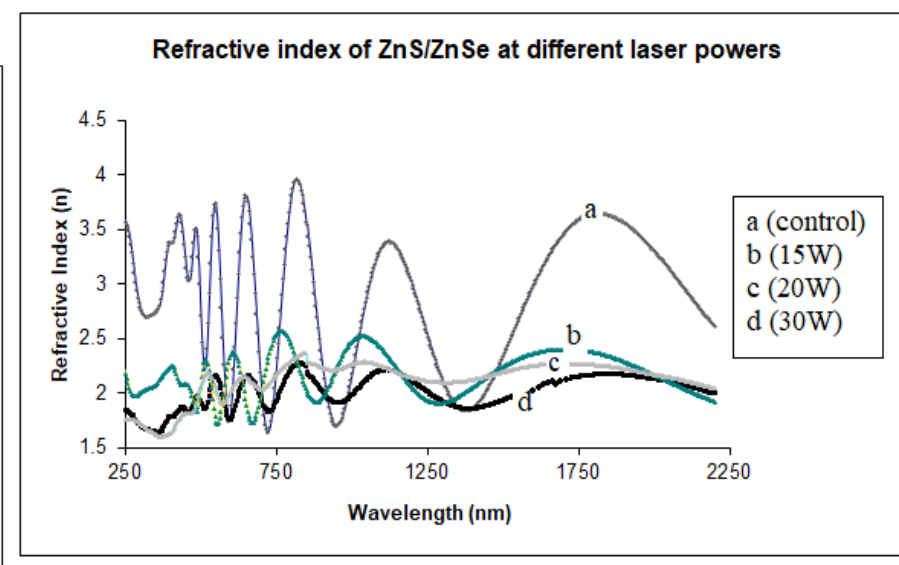

Figure 7: The refractive index (n) vs. wavelength before and after annealing at different laser powers. 
H. Howari, J. Mod. Mater.; Vol. 6, Issue 1, pp: 23-29, 2019

\section{X-ray Diffraction Measurements}

The $x$-ray diffraction spectra XRD of the prepared heterostructures were recorded using $\mathrm{Ni}$-filtered $\mathrm{Cu}-\mathrm{K}_{\alpha}$ radiation $(\lambda=0.154184 \mathrm{~nm})$ Philips X-ray diffractometer (model PW 1840). A range of $2 \theta$ was selected from $20^{\circ}$ to $100^{\circ}$ in order to detect all possible diffraction peaks. The XRD spectrum of the $\mathrm{ZnS}$ thin film is presented in Fig. (8), while Fig. (9), demonstrate the XRD spectrum of the ZnSe thin film. By comparing our experimental data with the ASTM cards of Xray powder, the peaks are categorized.

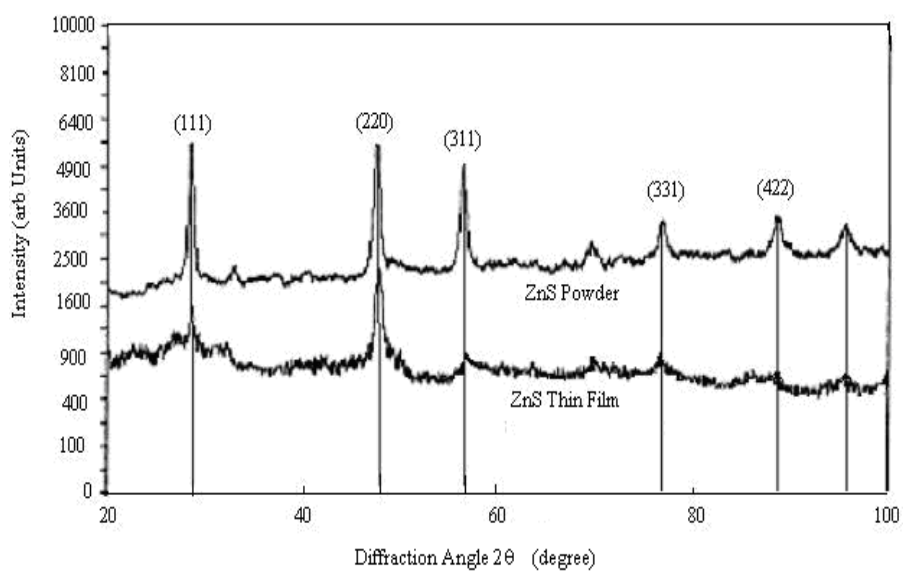

Figure 8: $X R D$ spectra of $Z n S$ powder and $Z n S$ thin film.

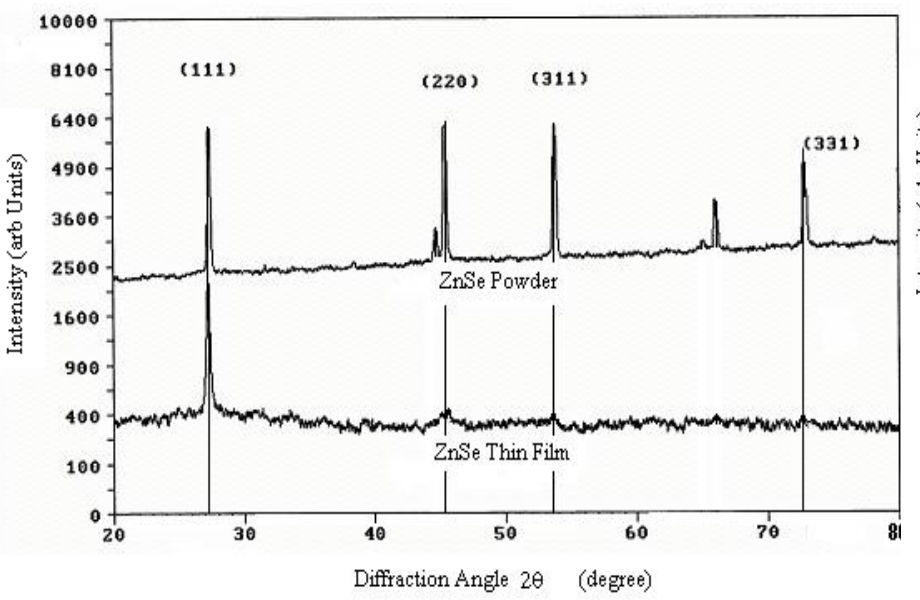

Figure 9: XRD spectra of ZnSe powder and ZnSe thin film.

The formed data of the $\mathrm{ZnS}$ and $\mathrm{ZnSe}$ thin films revealed good agreements with the data of $\mathrm{ZnS}$ and $\mathrm{ZnSe}$ powder file (JCPDS data number 090387 and 09-0345) corresponding to a cubic crystalline structure. Certainly, the typical peaks of the polycrystalline phase of $\mathrm{ZnS}$ and $\mathrm{ZnSe}$ films can be seen in XRD spectra. The ZnS thin film showed a Sphalerite structure [F43m (216)] with lattice parameter of $5.401 \AA$ as can be seen in Fig 8. Moreover, the $\mathrm{ZnSe}$ thin film displayed a Stilleite structure [F43m (216)] owing a lattice parameter of $5.668 \AA$ as illustrated in Fig 9. Likewise, a preferred growth along the $<111>$ direction is obvious [10]. Using Scherrer's formula, the crystallite sizes of the examined heterostructures were estimated:

$\mathrm{CS}=\frac{k \lambda}{\beta \cos \theta}$

where $\lambda$ is the wavelength of the $\mathrm{X}$-ray $(0.154184$ $\mathrm{nm}), \mathrm{k}$ is the shape factor $(\mathrm{k}=0.94), \mathrm{CS}$ is the crystallite size, $\beta$ is the corrected FWHM and $\theta$ is the corresponding angle. The average value of the crystallite size of $\mathrm{ZnS}$ has been estimated as $15 \pm 1 \mathrm{~nm}$. However, the results showed minor crystallite size about $12 \pm 1 \mathrm{~nm}$ in the case of $\mathrm{ZnS}$ powder. The average crystallite size of $\mathrm{ZnSe}$ has been determined as $13 \pm 1 \mathrm{~nm}$ and the results of the powder showed small value around $10 \pm 1 \mathrm{~nm}$. The $\mathrm{x}$-ray diffraction spectra of $\mathrm{ZnS} / \mathrm{ZnSe}$ heterostructures before (control) and after the annealing procedure at different laser powers $(15 \mathrm{~W}, 20 \mathrm{~W}$, and $30 \mathrm{~W})$ are shown in figure 10.

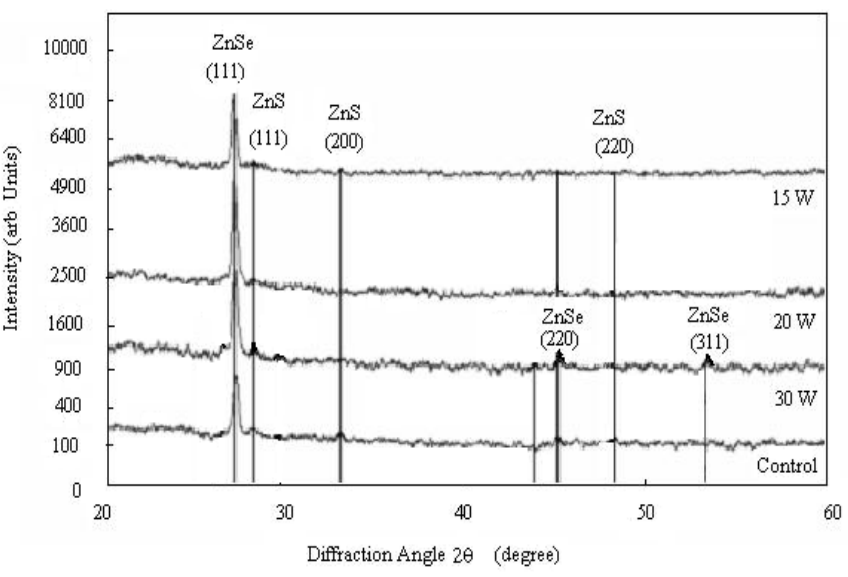

Figure 10: XRD spectra of the ZnS/ZnSe thin films before (control) and after the annealing at different laser powers.

XRD spectrum of the control sample shows an intense peak at an angle of 27.225 which is attributed to the (111) plane of $\mathrm{ZnSe}$ and also another peak at 45.196 attributed to the (220) plane of $\mathrm{ZnSe}$. Two peaks concerning the $\mathrm{ZnS}$ layer exist, one at 27.513 for the (111) plane and another at 33.088 for the (200) plane. Upon 
annealing at $15 \mathrm{~W}$, no changes are witnessed in the $\mathrm{x}$-ray spectrum. At $20 \mathrm{~W}$, little changes start to appear in the spectrum with a decrease in the intensities of the peaks. At $30 \mathrm{~W}$, the peaks become more noticeable as shown in the figure. Moreover, new peaks start to appear especially those remarked by Se at 29.704 for the (111) plane and another at 43.644 for the (102) plane of Se. The appearance of Se peaks is mainly attributed to the segregation of Se ions from their places leading to small islands within the film. This quite reasonable where Se melts at temperatures less than $\mathrm{Zn}$ therefore Se diffusion into the inner layer of $\mathrm{ZnS}$ occurs. This diffusion may lead to a new structure of $\mathrm{ZnSSe}[15,16]$.

\section{Results and Discussion}

Pulse laser annealing is a powerful technique for annealing out the damage in thin film structures and converting amorphous structures into polycrystalline or even single crystalline form [9]. When performing the annealing process, rapid heating and cooling occurs at the surface layers of the thin film which depends mostly on the laser pulse time which is in nanoseconds. More, the laser pulse penetrates only a very small distance into the film, therefore melting takes place at the surface area of the sample due to the large amount of heat delivered by the laser pulse. This melting is usually followed by recrystallization of the molten layer. Therefore, good annealing occurs only to the surface layers while the rest of the sample is unchanged. Moreover, pulsed laser annealing has the advantage over furnace annealing where the temperature rise is sufficient enough to dissociate the material [9-11].

Several samples of these thin films were annealed at three different laser powers 15, 20 and $30 \mathrm{~W}$ using $\mathrm{CO}_{2}$ pulsed laser provided with Q-Switch (single pulse) at a wavelength of $10600 \mathrm{~nm}$. We can see from the previous experimental results that reflection and transmission study of the prepared samples are very useful and powerful methods for studying phase transitions and knowing the influence of pulsed lasers on the optical properties of thin films. When the laser pulse is absorbed at the surface region of the target, it produces heat. This localized heat, which depends on the absorbed power, the laser pulse time and characteristics of the sample structure, can cause melting followed by recrystallization of the surface layers in extremely short times if the total pulse energy is sufficient to raise the temperature of the solid up to the melting threshold. Upon annealing at different laser powers, a decrease in the transmission (and reflectivity) occurs (figures 1 and 2) which means an increase in the absorption. A shift to higher wavelengths of the interference peaks is noticed and a decrease of the amplitude with increasing laser power (Fig.1), which is ascribed to the alterations of the morphology, structure and composition of the heterostructures after annealing. Figure (4) illustrates that when the laser power increases the absorption coefficient increases too for the whole wavelength range. This is mainly due to the heat effect of the pulsed laser on the $\mathrm{ZnS} / \mathrm{ZnSe}$ structure [16,17]. Again, this increase is accompanied with a shift towards higher wavelengths. This increase indicates that the quality of the samples is enhanced. X-ray diffraction spectra of the deposited thin films showed a polycrystalline phase of $\mathrm{ZnS}$ and $\mathrm{ZnSe}$ films [17, 18]. The $\mathrm{ZnS}$ thin film showed a Sphalerite structure with lattice parameter of $\mathrm{a}=$ $5.401 \AA$ while the ZnSe thin film showed a Stilleite structure having the lattice parameter of $\mathrm{a}=5.668 \AA$. Upon annealing at different laser powers of the $\mathrm{ZnS} / \mathrm{ZnSe}$ structures, little changes occur at 15 and $20 \mathrm{~W}$. The greatest change occurs at a power of $30 \mathrm{~W}$, where new little peaks start to appear in the x-ray diffraction pattern. This is due to the rapid heating and cooling of the surface which in turn led to recrystallization and another modified structure such as ZnSSe may start to appear [16].

\section{Conclusion}

Pulsed laser annealing was carried out on $\mathrm{ZnS} / \mathrm{ZnSe}$ thin films. Upon annealing, an increase in the absorption coefficient is observed which is due to an improvement in the granular nanostructure of the $\mathrm{ZnS} / \mathrm{ZnSe}$ heterostructures. The optical energy bandgaps of $\mathrm{ZnS}$ and $\mathrm{ZnSe}$ have been determined and estimated as $2.69 \mathrm{eV}$ for the $\mathrm{ZnSe}$ and $3.68 \mathrm{eV}$ for the $\mathrm{ZnS}$ respectively. XRD patterns of the deposited heterostructures before and after annealing 
H. Howari, J. Mod. Mater.; Vol. 6, Issue 1, pp: 23-29, 2019

showed an enhancement in the crystal structure where a preferential orientation with the (111) planes parallel to the substrate surface are observed.

\section{Competing Interests}

The author declared that no conflict of interest exists in the publication of this work.

\section{How to Cite this Article:}

H. Howari, "Pulsed Laser Annealing Effect on Optical and Structural Properties of $\mathrm{ZnS} / \mathrm{ZnSe}$ Heterostructures", J. Mod. Mater., vol. 6, no. 1, pp. 23-29, Oct. 2019. doi:10.21467/jmm.6.1.23-29

\section{References}

[1] R. Khenata, A. Bouhemadou, M. Sahnoun, Ali. H. Reshak, H. Baltache, M. Rabah, "Elastic, electronic and optical properties of $\mathrm{ZnS}, \mathrm{ZnSe}$ and $\mathrm{ZnTe}$ under pressure," Computational Materials Science vol. 38, pp. 29-38, 2006.

[2] H. Hilal Kurt and Evrim Tanriverdi, "Electrical Properties of $\mathrm{ZnS}$ and $\mathrm{ZnSe}$ Semiconductors in a PlasmaSemiconductor System," Journal of Electronic Materials, vol. 46, no. 7, pp. 3965-3975, 2017.

[3] M. E. POPA "Morphological, Structural, compositional and Raman Characterization of ZnSXSe1-X Thin Films Deposited by Quasi-Closed Volume Technique" Chalcogenide Letters, vol. 15, no. 9, pp. 441-449, 2018.

[4] Yi-Lin Sun, Dan Xie, Meng-Xing Sun, Chang-Jiu Teng, Liu Qian, Ruo Song Chen, Lan Xiang \& Tian-Ling Ren, "Hybrid graphene/cadmium free $\mathrm{ZnSe} / \mathrm{ZnS}$ quantum dots phototransistors for UV detection," Scientific Reports 8:5107.

[5] S. Thirumavalavan, K. Mani, S. Sagadevan, "A study of structural, morphological, optical and electrical properties of Zinc Selenide (ZnSe) thin film," Mater. Today Proc. 3, 2305e2314, 2016.

[6] O.G. Trubaieva, M.A. Chaika, and A.I. Lalayants, "The Growth, Structure and Luminescence Properties of ZnSe1-xSx Materials," Lithuanian Journal of Physics, vol. 58, no. 3, pp. 254-260 2018.

[7] Hisaaki Nishimura, Yuxin Lin, Yuki Kunimasa, and DaeGwi Kim "Preparation of ZnSe-ZnS alloy quantum dots by a hydrothermal method and their optical properties," IOP Conf. Series: Journal of Physics: Conf. Series1220, 012027 IOP Publishing 2019.

[8] Kai Ou, Shenwei Wang, Guangmiao Wan, Miaoling Huang, Yanwei Zhang, Liyuan Bai, Lixin Yi, "A study of structural, morphological and optical properties of nanostructured $\mathrm{ZnSe} / \mathrm{ZnS}$ multilayer thin films," Journal of Alloys and Compounds vol. 726, 707e711, 2017.

[9] H Howari, D Sands, J. E. Nicholls, J. H. C. Hogg, T. Stirner, and W. E. Hagston, "Excimer Laser Induced Diffusion in Magnetic Semiconductor Quantum Wells," J Appl Phys, vol 88, no.3, pp. 1373-1379, 2000.

[10] A.S. Hassanien, K.A. Aly, A.A. Akl, "Study of optical properties of thermally evaporated $\mathrm{ZnSe}$ thin films annealed at different pulsed laser powers," J. Alloys Compd. 685, 733e742, 2016.

[11] Umesh Khairnar1, Sulakshana Behere, Panjabrao Pawar, "Optical Properties of Polycrystalline Zinc Selenide Thin
Films," Materials Sciences and Applications, vol. 3, pp. 36-40, 2012.

[12] Xuan Truong Mai, Diem Thi Bui, Duykhanh Pham, Thanhthao Bui, Thanh Mien Nguyen4, Jinwoo Oh, Ngoc Quyen Tran, Bichthi Luong, "Study Of Single-Step Synthesis Of Hyperbranced Highly Luminescence Doped Znse:Mn, Znse:Mn/Zns Quantum Dots And Their Interactions With Acid Amine" American Journal of Engineering Research (AJER), vol. 7, no. 6, pp-27-32, 2018.

[13] Q. Zhang, H. Li, Y. Ma, T. Zhai, "ZnSe nanostructures: synthesis, properties and applications," Prog. Mater. Sci. 83, 472e535, 2016

[14] Bashir Mohi Ud Din Bhata, Khurshed A. Shahb, "Effect of Shell Thickness on Electron and Hole Transmission Probabilities of a ZnSe/ZnS Core- Shel Quantum Dot," Materials Research, vol. 21, no. 6, pp. 1-4, 2018.

[15] Anil Yadav, S. P. Nehra, Dinesh Patidar, "Synthesis, Characterization and Optical Properties of $\mathrm{ZnSe}$ Nanoparticles," International Journal of Applied Engineering Research, vol. 13, no. 6, pp. 4606-4609, 2018.

[16] A. Akl, S. A. Aly, H. Howari, "Structural characterization and optical properties of annealed ZnSSe thin films," Chalcogenide Letters, vol. 13, no. 6 , pp. 247-255, 2016.

[17] R. Ma, P.-J. Zhou, H.-J. Zhan, C. Chen, Y.-N. He, "Optimization of microwave assisted synthesis of highquality $\mathrm{ZnSe} / \mathrm{ZnS}$ core/shell quantum dots using response surface methodology", Opt. Commun. 291, 476e481, 2013.

[18] Mohammed Tareque Chowdhury, Md. Abdullah Zubair, Hiroaki Takeda, Kazi Md. Amjad Hussain, and Md. Fakhrul Islam, "Optical and structural characterization of ZnSe thin film fabricated by thermal vapor deposition technique," AIMS Materials Science, vol. 4, no. 5, pp. 1095-1121, 2017.

Publish your research article in AIJR journals-

$\checkmark \quad$ Online Submission and Tracking

$\checkmark$ Peer-Reviewed

$\checkmark$ Rapid decision

$\checkmark \quad$ Immediate Publication after acceptance

$\checkmark \quad$ Articles freely available online

$\checkmark \quad$ Retain full copyright of your article.

Submit your article at journals.aijr.in

Publish your books with AIJR publisher-

$\checkmark \quad$ Publish with ISBN and DOI.

$\checkmark$ Publish Thesis/Dissertation as Monograph.

$\checkmark$ Publish Book Monograph.

$\checkmark$ Publish Edited Volume/ Book.

$\checkmark$ Publish Conference Proceedings

$\checkmark \quad$ Retain full copyright of your books.

Submit your manuscript at books.aijr.org 